\title{
Distribution of the main malaria vectors in Kenya
}

\author{
Robi M Okara', Marianne E Sinka², Noboru Minakawa ${ }^{3}$, Charles M Mbogo ${ }^{4}$, Simon I Hay ${ }^{2}$, Robert W Snow ${ }^{1,5^{*}}$
}

\begin{abstract}
Background: A detailed knowledge of the distribution of the main Anopheles malaria vectors in Kenya should guide national vector control strategies. However, contemporary spatial distributions of the locally dominant Anopheles vectors including Anopheles gambiae, Anopheles arabiensis, Anopheles merus, Anopheles funestus, Anopheles pharoensis and Anopheles nili are lacking. The methods and approaches used to assemble contemporary available data on the present distribution of the dominant malaria vectors in Kenya are presented here.

Method: Primary empirical data from published and unpublished sources were identified for the period 1990 to 2009. Details recorded for each source included the first author, year of publication, report type, survey location name, month and year of survey, the main Anopheles species reported as present and the sampling and identification methods used. Survey locations were geo-positioned using national digital place name archives and on-line geo-referencing resources. The geo-located species-presence data were displayed and described administratively, using first-level administrative units (province), and biologically, based on the predicted spatial margins of Plasmodium falciparum transmission intensity in Kenya for the year 2009. Each geo-located survey site was assigned an urban or rural classification and attributed an altitude value.

Results: A total of 498 spatially unique descriptions of Anopheles vector species across Kenya sampled between 1990 and 2009 were identified, 53\% were obtained from published sources and further communications with authors. More than half (54\%) of the sites surveyed were investigated since 2005. A total of 174 sites reported the presence of An. gambiae complex without identification of sibling species. Anopheles arabiensis and An. funestus were the most widely reported at 244 and 265 spatially unique sites respectively with the former showing the most ubiquitous distribution nationally. Anopheles gambiae, An. arabiensis, An. funestus and An. pharoensis were reported at sites located in all the transmission intensity classes with more reports of An. gambiae in the highest transmission intensity areas than the very low transmission areas.

Conclusion: A contemporary, spatially defined database of the main malaria vectors in Kenya provides a baseline for future compilations of data and helps identify areas where information is currently lacking. The data collated here are published alongside this paper where it may help guide future sampling location decisions, help with the planning of vector control suites nationally and encourage broader research inquiry into vector species niche modeling.
\end{abstract}

\section{Background}

Human malaria parasites are transmitted by mosquitoes of the genus Anopheles and their geographic distribution is the result of a complex interaction of biogeography, including biotic (e.g. competition and dispersal) and abiotic factors (e.g. climate and topography) that can vary in both time and space. Africa has over 140

\footnotetext{
* Correspondence: rsnow@nairobi.kemri-wellcome.org

${ }^{1}$ Malaria Public Health and Epidemiology Group, Centre for Geographic Medicine, KEMRI - University of Oxford - Wellcome Trust Collaborative Programme, Kenyatta National Hospital Grounds, PO Box 43640-00100, Nairobi, Kenya
}

(c) 2010 Okara et al; licensee BioMed Central Ltd. This is an Open Access article distributed under the terms of the Creative Commons Attribution License (http://creativecommons.org/licenses/by/2.0), which permits unrestricted use, distribution, and reproduction in any medium, provided the original work is properly cited.

recorded Anopheles species, of which at least eight are considered to be effective vectors of malaria $[1,2]$. Two of the most efficient vectors of human malaria, Anopheles gambiae sensu stricto (hereafter An. gambiae) and Anopheles arabiensis [3] are members of the An. gambiae complex. Other recognized species of the complex are Anopheles merus, Anopheles melas, Anopheles quadriannulatus, Anopheles quadriannulatus B and Anopheles bwambae. Anopheles merus and An. melas are associated with salt-water with a localized distribution along the eastern and western coasts of Africa, respectively, while $A n$. bwambae has only been found breeding 
in mineral springs in the Semliki forest in Uganda [4]. Anopheles quadriannulatus, found in south-east Africa [4] and An. quadriannulatus B, which has been described in Ethiopia [5] are not considered vectors of human malaria as they are generally zoophilic [4]. In addition to the An. gambiae complex, other species known to be important in malaria transmission in Africa include Anopheles nili, Anopheles moucheti and Anopheles funestus which belongs to the Funestus group of which there are two African subgroups (Funestus subgroup includes Anopheles aruni, Anopheles confusus, Anopheles funestus, Anopheles parensis, Anopheles vaneedeni; Rivulorum subgroup includes Anopheles brucei, Anopheles fuscivenosus, Anopheles rivulorum, and $A n$. rivulorum-like species) $[1,6]$. Other species, such as Anopheles paludis, Anopheles mascarensis and Anopheles hancocki play only a limited, secondary and localized role where they are found [7].

Several of these vector species are found to occur in sympatry in much of Africa and their importance in malaria transmission varies depending on behaviour (e.g. biting activity, feeding and resting preferences), seasonal prevalence and vectorial capacity $[4,7]$. These differences contribute to the varied malaria epidemiological patterns observed in Africa and, subsequently, different areas may require different tools and strategies for optimal vector control.

The main tools of vector control in many malaria endemic countries in Africa are based on reducing vector-human contact with insecticide-treated nets (ITNs), long-lasting insecticidal nets (LLINs) and indoor residual spraying (IRS). There is also renewed interest in integrated vector control approaches that can combine complimentary aspects of vector control and environmental management [8-13]. One of the key elements outlined by the global strategic framework for integrated vector management (IVM) is for "an evidence-based decisionmaking approach which involves the adaptation of strategies and interventions to local vector ecology, epidemiology and resources that are guided by operational research and subject to routine monitoring and evaluation" [14]. A detailed knowledge and understanding of the malaria vector species' distribution, abundance, and behaviour is therefore relevant in understanding their role in malaria transmission and hence its control. Such baseline knowledge is also necessary in the monitoring and evaluation of the effects of control methods in an area and in the surveillance of insecticide resistance in vector species. Knowledge of the distribution of vectors in areas with no current malaria transmission is also important in defining where the potential for transmission exists, should malaria be introduced. Unfortunately, contemporary species distribution information is not readily available for many countries, especially on the
African continent where malaria is among the leading causes of mortality and morbidity $[15,16]$.

The last map of the distribution of Anopheles vectors in Kenya was published over 30 years ago and shows the distribution of the An. gambiae complex and $A n$. funestus [17] (Figures 1a and 1b). Various social, demographic and environmental changes have occurred in Kenya since its publication, which may have substantially influenced these vectors' distribution. Moreover, advanced species identification techniques have enabled several species complexes and groups to be identified to their sibling or sub-species, most significantly the $A n$. gambiae complex. This is of relevance as these closely related species, which are difficult to distinguish morphologically, are known to vary in their ability to transmit malaria [4]. In addition, other malaria vector species found in Kenya, such as An. pharoensis and An. nili, are known to play a restricted role in malaria transmission and their national distribution has not been previously defined.

Kenya is fortunate to have had a productive malaria research community since the 1940s. The harnessing of data on anti-malarial drug sensitivity $[18,19]$, health service providers [20] and malaria infection risks [21] into useable formats within a spatial dimension has become a priority of the Ministry of Public Health \& Sanitations' Division of Malaria Control to define appropriate subnational strategies for malaria control through to 2017 . This paper presents the methods and approaches used to assemble contemporary data on the modern day distribution of the dominant malaria vectors in Kenya. Knowledge of the local distributions of these species will help facilitate the application of appropriate modes of malaria control and maximize the use of limited resources.

\section{Methods}

A systematic collation of primary empirical occurrence data for the main malaria vectors in Kenya from published and unpublished sources was initiated in June 2008 to assemble a national database of the distribution of these vectors. Five malaria vector species, namely $A n$. arabiensis, An. gambiae and An. merus of the An. gambiae complex, the combined sibling species of the $A n$. funestus complex and An. nili, were selected as the main vector species in Kenya to be addressed. They are considered in a number of authoritative reviews [22-26] to be among the most important vectors of human malaria where they are found by virtue of their competence as vectors, average sporozoite rates, preference for feeding on humans and abundance [27]. Anopheles pharoensis was not universally considered a dominant vector species by these reviews but promoted for inclusion because of its local importance in Kenya $[28,29]$. The 


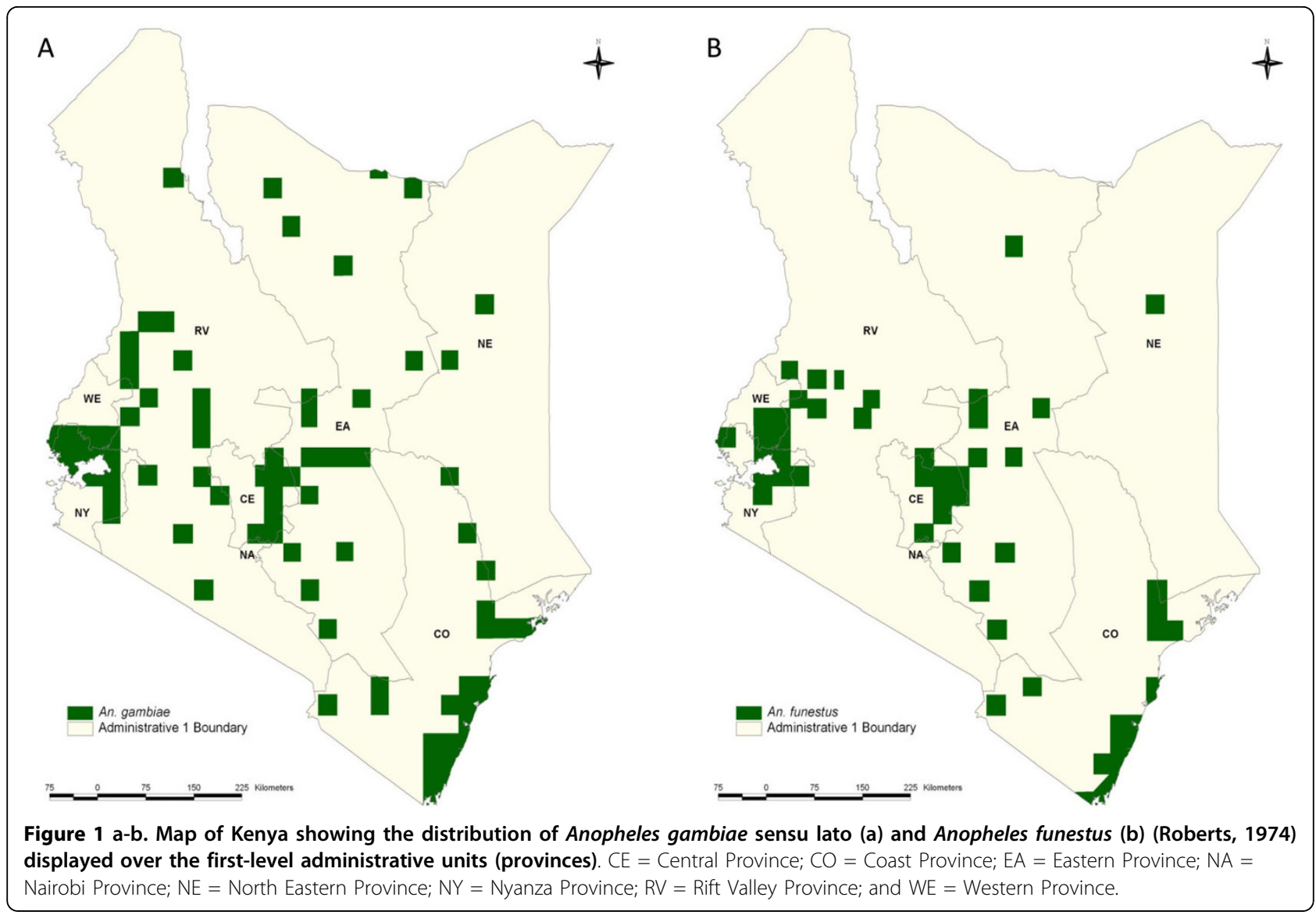

aim was to define the spatial distribution of reported presence of these six vectors documented through entomological surveys since January 1990. This time limit was chosen to ensure that the data collected were representative of the contemporary distribution of these Anopheles vectors and included the most recent taxonomical classifications and the most accurate techniques for species identification.

\section{Search strategy}

The search strategy followed those general approaches developed by the Malaria Atlas Project (MAP) [30] and are outlined in detail elsewhere [27]. Briefly, the search was conducted using the following sequential approaches: i) an electronic search using online bibliographic archives, PubMed [31] and Web of Science [32] with "Anopheles"Kenya" as search terms to identify studies that sampled for anophelines. Additional searches were made within specific vector resources including AnoBase [33], the Disease Vector Database [34], Lifemapper [35], Mapping Malaria Risk in Africa [36] and VectorBase [37]. Email alerts for all relevant citation websites including Malaria World [38], Malaria in the News (Roll Back Malaria Partnership) [39], Malaria
Bulletin (USAID Environmental Health Project) [40] and BioMed Central [41] were set up to receive weekly updates of any new relevant articles; ii) a review of the Walter Reed Biosystematics Unit (WRBU) mosquito catalogue reference database [42]; iii) a review of extensive paper archives of the Kenya Ministry of Public Health and Sanitation's Division of Vector Borne and Neglected Tropical Diseases (DVBNTD) in Nairobi; iv) a review of selected bibliographies [23]; v) a review of postgraduate theses from the Department of Pathology at Kenyatta University in October 2009; and vi) direct contact with local research networks known to be active in vector research and/or control in Kenya to review the database and augment with personal data and/or identify known gaps.

\section{Data abstraction}

Reference source material was reviewed by RMO and MES to identify location-specific information for identified species. For each source, the first author, year of publication, and source/report type were recorded and specific details relating to the vector surveys were extracted, including the survey date, duration of the sampling effort in months, the sampling method (larval 
searches, indoor house catches, baited traps etc), primary identification methods (e.g. morphology to identify a species complex) and further identification (e.g. PCR methods to identify sibling species within a species complex). Mosquito abundance, sporozoite rates, blood meal identification or gravidity were not recorded as the objective was only to define species presence. Moreover, the methods reported for more detailed vector dynamics were both variable and incomplete across the series. Given the location of several national malaria research groups, there are some communities where multiple records exist through time. Only the most recent data from each community were included, given the dynamics of change reported in vector species composition over the last ten years in East Africa [43,44].

\section{Geo-positioning of surveyed locations}

Survey location data provided in the source material were used in combination with digital place name archives and on-line geo-reference resources to provide a digital longitude, latitude and extent for each survey site. The digital resources, based on Global Positioning System (GPS) defined locations, included a national schools database developed through a mapping project in 2008 by the Ministry of Education [45]; a database of settlements connected to the classified motorable road network compiled as part of a road mapping project by the Ministry of Roads and Public Works [46]; and a variety of smaller databases developed as part of research projects or development programmes. In addition, a database of villages digitized from topographical maps in 2002 was obtained from the International Livestock Research Institute. These databases were used to geo-position survey locations with priority given to the GPS sources. Where survey locations could not be geopositioned from any of these national databases, digital databases such as Microsoft Encarta [47], Google Earth [48], the GEOnet Names Server [49] and Global Gazetteer [50] were used (see [27] for details). A database of enumeration areas for the 1999 census obtained from the Kenya National Bureau of Statistics was used as a final source if survey locations could not be found. Survey location extents were classified as points if they could be positioned to an area $\leq 10 \mathrm{~km}^{2}$; a wide area $\left(>10 \mathrm{~km}^{2}\right.$ to $\left.<25 \mathrm{~km}^{2}\right)$; or polygon $\left(\geq 25 \mathrm{~km}^{2}\right)$ [51].

\section{Data displays and summaries}

All geo-located species-presence data were displayed in ArcGIS 9.2 (ESRI, Redlands, CA, USA). Two descriptions of spatial distributions were used to summarize the available data between 1990 and 2009: administrative and biological. First, digital boundary files were created for the first-level administrative units (province) to display and describe the distribution of vector species information. Second, the spatial margins of the 2009 predictions of $P$. falciparum transmission intensity, modeled at $1 \times 1 \mathrm{~km}$ resolutions on the basis of a community-based parasite prevalence in children aged two to ten years $\left(P f \mathrm{PR}_{2-10}\right)$, were used to classify entomological survey data locations and displayed by $P f \mathrm{PR}_{2-10}>=$ 40\%; PfPR $2-10$ between $5 \%$ and $39 \%$; $P f \mathrm{PR}_{2-10}$ between $0.1 \%$ and $5 \%$; and $P f \mathrm{PR}_{2-10}<0.1 \%$ [21]. Urban-rural classifications of survey locations followed criteria described elsewhere [21] and were defined by the urban-rural extents used during the 1999 national census definitions of enumeration areas (EA) and digitized for the majority of the country [52]. Finally each point was attributed to an altitude value in meters above sea level using an altitude map of $30 \times 30 \mathrm{~m}$ spatial resolution developed from satellite imagery by the Shuttle Radar Topography Mission (SRTM) project of the US National GeospatialIntelligence Agency (NGA) and the National Aeronautical and Space Administration (NASA), downloaded from Virtual Terrain Project [53].

\section{Results}

The search strategy identified a total of 498 spatially unique descriptions of Anopheles vector species across Kenya sampled between 1990 and 2009. Of these, 265 $(53 \%)$ of the site-specific data were obtained from peerreviewed published sources and further communications with authors, information on one site $(0.2 \%)$ was identified from a conference abstract, eight sites (1.6\%) were identified from five doctoral and masters theses, 27 sites (5.4\%) from Ministry of Health reports, 21 sites (4.2\%) from other reports and 176 sites (35\%) from investigations undertaken by national research partners and provided as unpublished data to this project. Two hundred and sixty locations were surveyed for adult vectors using sampling methods including indoor pyrethrum spray catches, room searches, light traps or exit traps; 196 sites were investigated using only larval sampling from suspected breeding sites; and 42 sites were investigated using a combination of adult and larval vector sampling. Species identification was based only on morphological examinations at 194 (39\%) sites, PCR methods (alone and in combination with other techniques) at 298 (60\%) sites and DNA probes at only six sites. There was inadequate information or ambiguity concerning the precise community name of five sites (1\%) so these could not be geo-located and were excluded from the descriptive analysis. One site recorded information across a large area in excess of $25 \mathrm{~km}^{2}$ and was also excluded.

The data spanned the entire time-series from 1990 through to 2009 (Table 1). The majority of data (75\%) described vector occurrence after 2000, with 266 (54\%) of the sites recording information over the last five years (2005 - 2009 inclusive). Despite a reasonably wide 
Table 1 Spatially unique survey sites reporting Anopheles species presence in Kenya by survey date, location and methods of sampling and detection

\begin{tabular}{|c|c|c|c|c|c|c|}
\hline Species & An. gambiae & An. arabiensis & An. merus & An. funestus & An. pharoensis & An. nili \\
\hline \multicolumn{7}{|l|}{ Survey period } \\
\hline $1990-1994$ & 7 & 7 & 2 & 29 & 9 & 9 \\
\hline $1995-1999$ & 50 & 34 & 20 & 27 & 1 & 0 \\
\hline $2000-2004$ & 46 & 42 & 4 & 81 & 3 & 0 \\
\hline $2005-2009$ & 41 & 143 & 1 & 94 & 20 & 1 \\
\hline \multicolumn{7}{|l|}{ Province } \\
\hline Central & 1 & 26 & 0 & 14 & 4 & 1 \\
\hline Coast & 39 & 35 & 27 & 89 & 14 & 9 \\
\hline Eastern & 2 & 7 & 0 & 3 & 1 & 0 \\
\hline Nairobi & 0 & 9 & 0 & 0 & 0 & 0 \\
\hline North Eastern & 0 & 0 & 0 & 0 & 0 & 0 \\
\hline Nyanza & 78 & 127 & 0 & 111 & 18 & 0 \\
\hline Rift Valley & 16 & 29 & 0 & 28 & 0 & 0 \\
\hline Western & 17 & 11 & 0 & 20 & 0 & 0 \\
\hline \multicolumn{7}{|l|}{ Site Type } \\
\hline Urban & 20 & 26 & 5 & 23 & 1 & 1 \\
\hline Rural & 133 & 218 & 22 & 242 & 36 & 9 \\
\hline \multicolumn{7}{|l|}{ Transmission intensity } \\
\hline High PfPR $R_{2-10}>=40 \%$ & 49 & 68 & 0 & 54 & 4 & 0 \\
\hline Moderate PfPR $2-10$ 5-39\% & 25 & 53 & 0 & 24 & 13 & 0 \\
\hline Low PfPR $R_{2-10} 0.1<5 \%$ & 74 & 73 & 27 & 164 & 15 & 9 \\
\hline Very low PfPR $_{2-10}<0.1 \%$ & 5 & 50 & 0 & 23 & 5 & 1 \\
\hline \multicolumn{7}{|l|}{ Collection method } \\
\hline Adults & 120 & 110 & 22 & 179 & 16 & 10 \\
\hline Larvae & 26 & 124 & 2 & 50 & 17 & 0 \\
\hline Adults \& Larvae & 7 & 10 & 3 & 36 & 4 & 0 \\
\hline \multicolumn{7}{|l|}{ Identification method } \\
\hline Morphology only & 17 & 14 & 1 & 139 & 17 & 10 \\
\hline Polymerase chain reaction & 136 & 224 & 26 & 121 & 20 & 0 \\
\hline Chromosome banding sequences & 4 & 6 & 2 & 8 & 0 & 0 \\
\hline DNA probe method & 0 & 6 & 0 & 5 & 0 & 0 \\
\hline Total & 153 & 244 & 27 & 265 & 37 & 10 \\
\hline
\end{tabular}

national distribution (Figure 2), data were inevitably over-distributed around malaria research centres and their study populations in Kilifi, Malindi, Kwale, Suba, Siaya, Bondo, Kisii and Gucha districts. These eight of the 49 district boundaries, defined in 1999 by the national census bureau, provided 311 (63\%) of the sampled site-specific Anopheles presence data.

A total of 174 sites reported the presence of the $A n$. gambiae complex without specification of the sibling species. One hundred and fifty three survey locations reported the presence of $A n$. gambiae and these were largely located in areas of Western and Nyanza Provinces closest to Lake Victoria and in the Coast Province with few presences reported in the more central regions of the country (Table 1; Figure 3a). Of these reports 17 An. gambiae were identified using morphology only with the remainder identified using speciesspecific chromosomal PCR and cytogenetic techniques involving analysis of polytene chromosome banding patterns (CBS). The majority $(120,78 \%)$ of reported $A n$. gambiae presences were based on adult catches.

Anopheles arabiensis was more ubiquitous in its reported distribution with observations along the coast, across Western Kenya and central Kenya including the arid areas of the north west in Turkana district (Table 1; Figure 3b), with 244 unique spatial incidences of this sibling species reported since 1990. Anopheles arabiensis larvae were sampled at $124(51 \%)$ sites, adult catches 


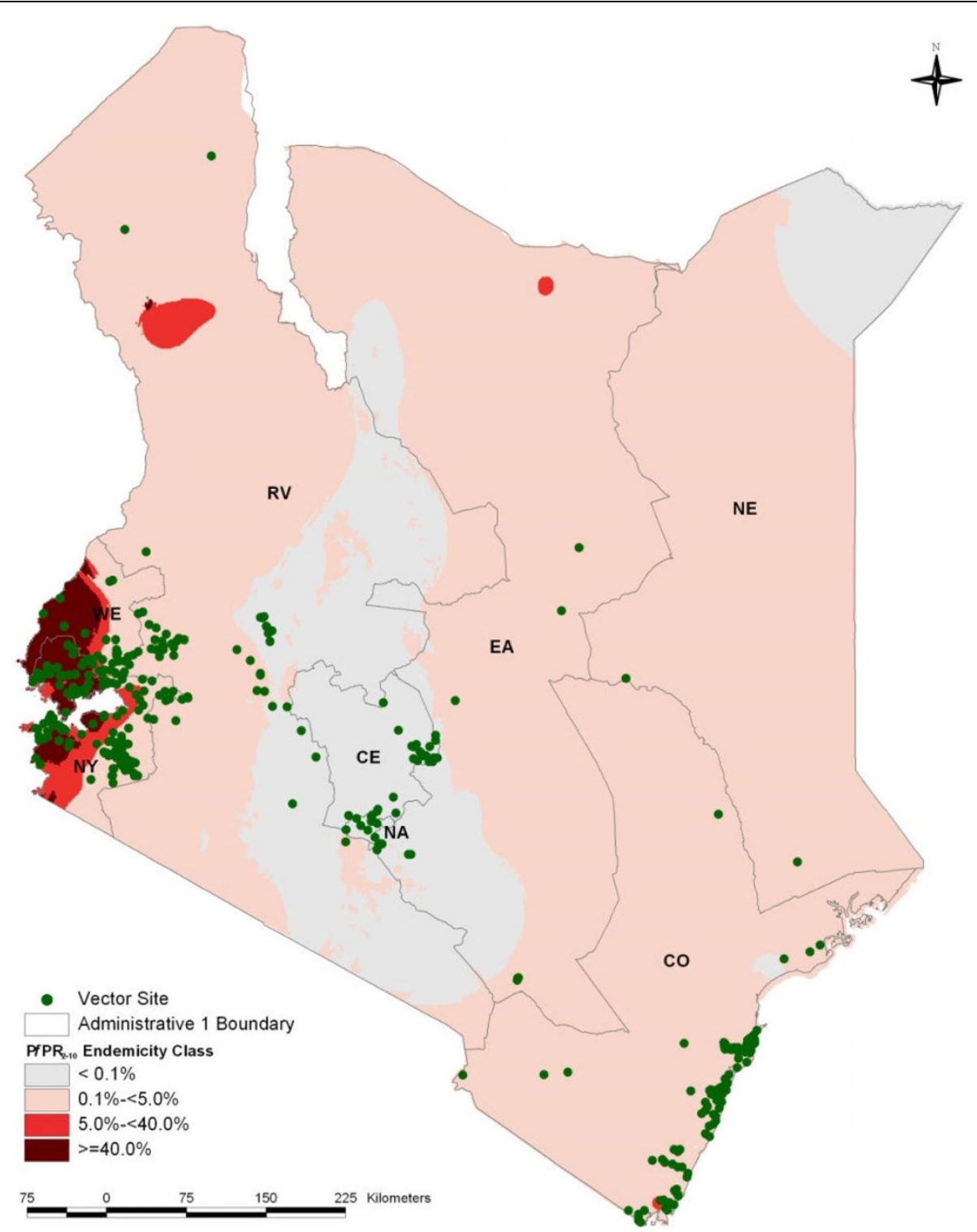

Figure 2 Map of Kenya showing the distribution of 492 spatially unique survey sites displayed over the first-level administrative units (Provinces) and the predicted $P f R_{2-10}$ endemicity classes: $P f R_{2-10}>=40 \% ; P f P R_{2-10} 5-39 \% ; P f P R_{2-10} 0.1 \%<5 \%$; and $P f P R_{2-10}<0.1 \%$ [21] as shown in Figure legend.

were conducted at $110(45 \%)$ sites and a combination of larval and adult sampling methods were used at ten (4\%) sites. Fourteen (6\%) An. arabiensis samples were identified by morphological examination alone, 224 (92\%) were identified using PCR and samples from six sites used DNA probes (Table 1).

Anopheles merus was reported at 27 sites between 1990 and 2008, all of which were located on the Kenyan coast reflecting the salt water larval conditions associated with this species. The majority of reported samples were adults identified using PCR (Table 1; Figure 3c).
Besides the An. gambiae complex, An. funestus complex was also widely reported, being identified at a total of 265 sites distributed at the Coast, in central regions and, more frequently than other Anopheles, in the highland areas distal to Lake Victoria in Western and Nyanza Provinces (Table 1; Figure 3d). The majority of An. funestus complex positive sites were from adult catches (68\%). Fewer studies (19\%) reported larval survey results and only $14 \%$ of reported occurrences were based on a combination of adult and larval surveys. Information on the sibling species for this vector was not widely reported and it is therefore presented here as 


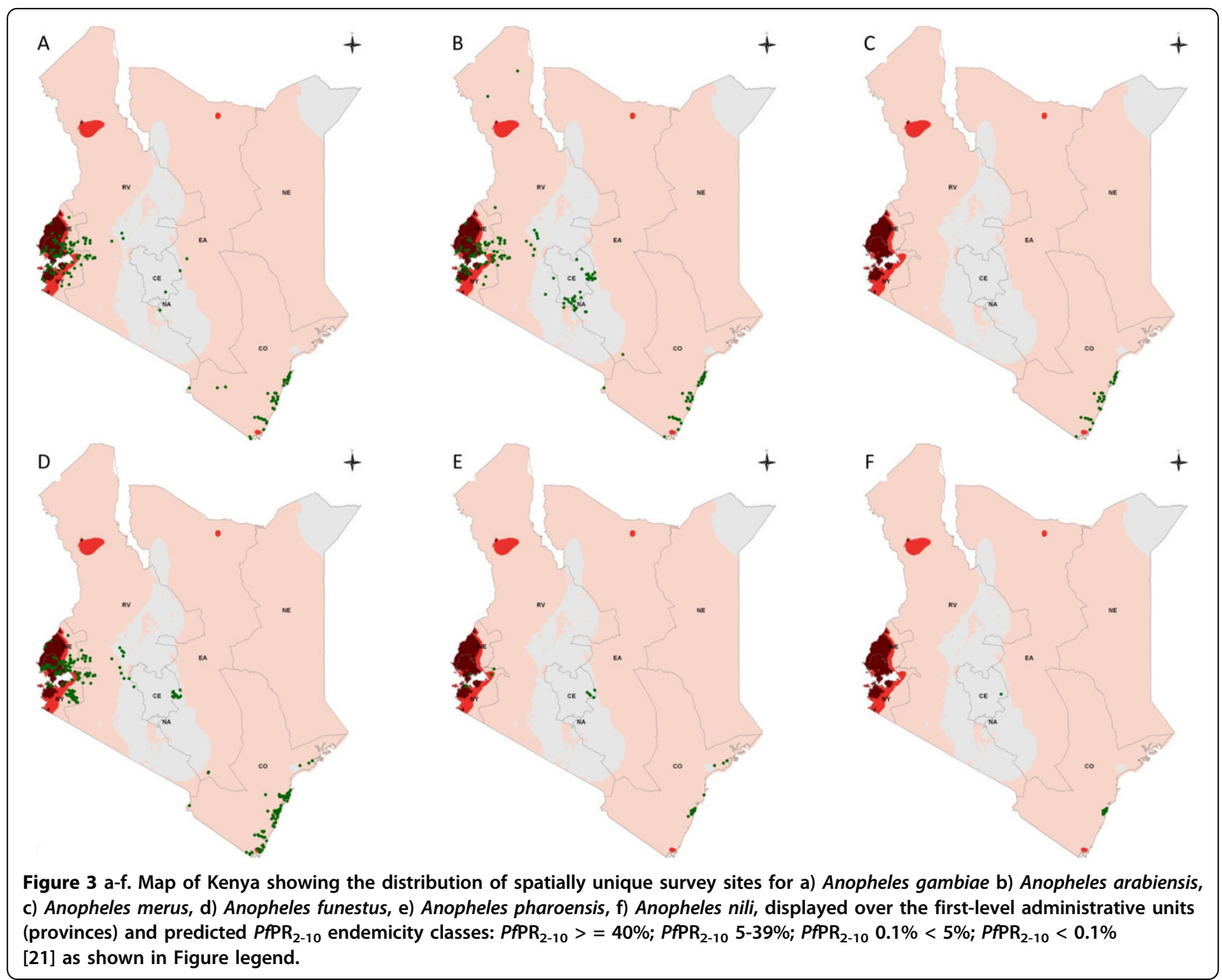

the complex. Morphological identification was used for samples from 139 (52\%) sites, PCR at 121 (46\%) sites and DNA probes at five (2\%) sites. Anopheles nili and $A n$. pharoensis were rarely documented in the assembled vector studies (Table 1). Anopheles pharoensis were identified from 37 sites in districts along the coast (14 sites), at four sites in Kirinyaga District in Central Province, at one site in Mbeere District in Eastern Province and from 18 sites in Nyanza Province including Suba, Nyando, Kisumu and Bondo districts. Seventeen studies identified this vector using morphology and the remainder used PCR. Anopheles nili was only found in ten sites where it was identified morphologically from adult catches. Nine of these sites were at Kilifi on the Kenyan Coast and one was in Kirinyaga in Central Province.

From peer-reviewed sources, other anopheline species documented included Anopheles christyi, Anopheles coustani, Anopheles demeilloni, Anopheles gibbinsi, Anopheles harperi, Anopheles implexus, Anopheles maculipalpis, Anopheles marshalli, Anopheles pretoriensis,
Anopheles rufipes, Anopheles squamosus, Anopheles swahilicus, Anopheles theileri, Anopheles wilsoni and Anopheles ziemanni, none of which are considered as important or primary vectors in Africa [22-26].

Of the 492 sites where vector data were documented, 53 were classified as urban extents. Interestingly, 20 (38\%) of these documented the presence of An. gambiae including Kisumu, Kisii, Kilifi and Malindi towns. Twenty-six urban sites (49\%) reported the presence of $A n$. arabiensis, five sites reported the presence of $A n$. melas at the coast and 23 (43\%) sites reported the presence of An. funestus complex. At the 58 sites located in the lowest transmission intensity class $\left(P f \mathrm{PR}_{2-10}<0.1 \%\right.$; Figure 2) five (9\%) reports of An. gambiae were documented while $50(86 \%)$ of the sites reported $A n$. arabiensis and 23 (40\%) reported the presence of $A n$. funestus complex. There were 121 sites of vector occurrence in areas of the highest malaria transmission intensity, with predicted $P f \mathrm{PR}_{2-10}>=40 \%$ (Figure 2). Here 49 (40\%) documented the presence of An. gambiae, 68 
(56\%) sites reported the presence of An. arabiensis and 54 (45\%) sites reported the presence of An. funestus complex. Thirteen locations were situated higher than 2,000 m above sea level and An. gambiae, An. arabiensis and $A n$. funestus complex were all identified at these altitudes.

\section{Discussion}

There have been a number of efforts to assemble information on the spatial distributions of dominant malaria vectors regionally $[26,54,55]$ and to model vector distributions at a continental scale [34,56-58]. These databases, however, are limited in their spatial scope of information for national-level vector distribution mapping, modeling and decision-making. At national scales there have been more intensive efforts to map the distributions of major malaria vectors, for example, in Nigeria [59], Mali [60,61], Mauritania [62], Niger [63], Eritrea $[64,65]$ and Cameroon [66]. This nascent literature on national mapping of malaria vectors signals a growing recognition that these data are necessary to design, monitor and tailor future control options.

In Kenya, the last national malaria vector map was generated using survey data of unknown origin in 1974 [17] (Figure 1). The contemporary database presented here details the distribution of malaria vector species from 492 unique spatial locations across Kenya from surveys undertaken since 1990. These data show that where adult and larval vectors have been identified, the most widespread Anopheles species are An. arabiensis and An. funestus complex, identified across most provinces, transmission intensities and urban-rural extents of Kenya (Table 1; Figures 3b and 3d). The spatial occurrence of the three most dominant vectors vary between different classifications of transmission intensity, for example, An. gambiae was documented more often in areas with the highest transmission intensity, with less frequent reports at sites in very low transmission areas. The ubiquitous extent of An. arabiensis in both urban and rural settings has important implications for the broader success of vector control approaches promoted in Kenya. Anopheles arabiensis is a vector that predominantly rests outdoors with a general preference for biting animals, which may have implications for the expansion of IRS into areas where transmission intensity is high and demands accelerated attacks on the vectorial capacity [67]. There are also suggestions that this sibling species of the An. gambiae complex is beginning to dominate over An. gambiae in recent years, coincidental with expanded ITN coverage across East Africa (Nabie Bayoh, personal communication). The reports of An. gambiae in urban areas are particularly striking, based on accepted knowledge of this species' habitat, however this may reflect differences in the definition of "urban" found in previous literature that describe the relative absence of this vector in urban settlements [68-70] or may suggest that this dogma is incorrect in a Kenyan context [71,72].

Assembling a contemporary, spatially defined database of malaria vector occurrence provides the platform for more systematic future compilations of data and serves as a means to identify areas where information is currently lacking. Notable perhaps is the lack of information on the presence of malaria vectors from areas where transmission intensity is moderate-to-high where there appear to have been no reported entomological surveys over the last 20 years. These include areas located along the Tana River (an area of known transmission dividing Eastern and North Eastern provinces) and the entire region of North Eastern Kenya (Figure 2). As expected, across areas of traditionally very low transmission, there have been relatively few surveys of the endemic malaria vector populations possibly because they are difficult to undertake where vector abundance is low, acutely seasonal or spatially over-dispersed. Nevertheless knowledge of vector distribution, composition and bionomics is still valuable in helping to guide vector control recommendations in these otherwise neglected areas.

The database described here only includes vector presence data, as true absences can be difficult to classify unless reports specifically mention that a vector had not been found. Presence-only data provides a challenge for those geo-spatial mapping techniques aimed at predicting vector distributions across areas with no data. Most species mapping techniques currently available (reviewed in [73]) relate species occurrence records to environmental variables retrieved from those locations and use these relationships to predict the probability of presence at un-sampled locations where equivalent environmental conditions occur [74,75]. A major assumption of these techniques is that the distribution of occurrence records sampled is representative of the species niche, which is rarely the case when models are applied at a national scale. The reliability of vector species maps could be greatly improved with a more systematic, randomly sampled national level reconnaissance using systematic standardized approaches to collection and species identification. It was notable that for 174 sites it was not possible to refine information below the An. gambiae species complex. With the known diversity in bionomics between sibling species, detailed sibling-specific data are needed to ensure the application of successful and targeted vector control. An issue that could be easily surmountable with the adoption of standardized techniques for speciation included in all national surveillance programs. Rapid vector surveillance methods should be 
guided by the geographical distribution of existing occurrence records to design sampling frames and increase the fidelity, temporal and spatial resolutions of key vector intelligence. In this vein, it is hoped that future surveys will benefit from this current study and from work in progress predicting the species range of 41 global dominant Anopheles vector species, currently being undertaken as part of the wider activities of the Malaria Atlas Project [27].

The data described here are available for wider use by the national malaria control programme and its partners under the similar principles of spatial data assembly and archiving completed for health facility locations [20] and parasite prevalence among communities across Kenya [21]. Providing open access to data assemblies will hopefully encourage investigations into areas of poor data, stimulate interest in and promote the design of a systematic national vector sampling program whilst providing a platform for future data sharing. This latter point is of particular importance as for this study, the research community were, in the most part, generous in sharing unpublished data, with only a few exceptions who considered data sharing a threat to their own scientific output. All the assembled data accompanying this publication has been released into the public domain [76] for use by the wider research and control communities.

\section{Acknowledgements}

We are grateful for the help provided by a large number of malaria scientists working in Kenya in helping identify and geo-locate the information summarized in this paper: Joseph Mwangangi, Ulrike Fillinger, John Gimnig, Maurice Ombok, Chandy John, Stephen Munga, Nabie Bayoh, Kyoko Futami, Annabel Howard, Kiambo Njagi, Ephantus Kabiru, Davis Wachira, Samuel Muiruri, Dunstan Mukoko and the Division of Vector Borne and Neglected Tropical Diseases of Ministry of Public Health and Sanitation. Victor Alegana is thanked for his help in providing GIS support and Will Temperley for help with database extractions. The authors wish to acknowledge the continued support of Elizabeth Juma of the Division of Malaria Control, Kenya. The authors acknowledge the support of the Kenya Medical Research Institute (KEMRI) and this paper is published with the permission of the director of KEMRI. RMO is funded by a Wellcome Trust Masters Training Fellowship (\#083124). MES is funded by a Wellcome Trust project grant to SIH (\#083534). SIH is funded by a Senior Research Fellowship from the Wellcome Trust (\#079091). RWS is a Wellcome Trust Principal Research Fellow (\#079080). The work forms part of the output of the Malaria Atlas Project (MAP, http://www.map.ox.ac.uk), principally funded by the Wellcome Trust, U.K.

\section{Author details}

${ }^{1}$ Malaria Public Health and Epidemiology Group, Centre for Geographic Medicine, KEMRI - University of Oxford - Wellcome Trust Collaborative Programme, Kenyatta National Hospital Grounds, PO Box 43640-00100, Nairobi, Kenya. ${ }^{2}$ Spatial Ecology and Epidemiology Group, Tinbergen Building, Department of Zoology, University of Oxford, South Parks Road, Oxford, OX1 3PS, UK. Institute of Tropical Medicine (NEKKEN) and the Global Center of Excellence Program, Nagasaki University, 1-12-4 Sakamoto, Nagasaki, Nagasaki 852-8523, Japan. ${ }^{4} \mathrm{KEMRI}$, Centre for Geographic Medicine Coast, PO Box 230, Kilifi, Kenya. ${ }^{5}$ Centre for Tropical Medicine, Nuffield Department of Clinical Medicine, University of Oxford, CCVTM, Oxford OX3 7ப, UK.

\section{Authors' contributions}

RWS and SIH conceived the study and managed its design and implementation. RMO wrote the first draft of the manuscript and assembled the occurrence data, with assistance from MES, and performed the data analysis and mapping. All authors participated in editing of the manuscript and approved the final manuscript.

\section{Competing interests}

The authors declare that they have no competing interests.

Received: 20 January 2010 Accepted: 4 March 2010 Published: 4 March 2010

\section{References}

1. Gillies MT, Coetzee M: A Supplement to the Anophelinae of Africa South of the Sahara Johannesburg: The South African Institute for Medical Research 1987, 55.

2. Gillies MT, de Meillon B: The Anophelinae of Africa South of the Sahara (Ethiopian zoogeographical region) Johannesburg: The South African Institute for Medical Research 1968, 54.

3. White GB: Anopheles gambiae complex and disease transmission in Africa. Trans Roy Soc Trop Med Hyg 1974, 68:278-302.

4. Coluzzi M: Heterogeneities of the malaria vectorial system in tropical Africa and their significance in malaria epidemiology and control. Bull World Health Organ 1984, 62:107-113.

5. Hunt RH, Coetzee M, Fettene M: The Anopheles gambiae complex: a new species from Ethiopia. Trans R Soc Trop Med Hyg 1998, 92:231-235.

6. Harbach RE: The classification of genus Anopheles (Diptera: Culicidae): a working hypothesis of phylogenetic relationships. Bull Entomol Res 2004, 94:537-553.

7. Fontenille D, Simard F: Unravelling complexities in human malaria transmission dynamics in Africa through a comprehensive knowledge of vector populations. Comp Immunol Microbiol Infect Dis 2004, 27:357-375.

8. Fillinger U, Kannady K, William G, Vanek MJ, Dongus S, Nyika D, Geissbuehler Y, Chaki PP, Govella NJ, Mathenge EM, Singer BH, Mshinda H, Lindsay SW, Tanner M, Mtasiwa D, de Castro MC, Killeen GF: A tool box for operational mosquito larval control: preliminary results and early lessons from the Urban Malaria Control Programme in Dar es Salaam, Tanzania. Malar J 2008, 7:20.

9. Geissbühler Y, Chaki P, Emidi B, Govella NJ, Shirima R, Mayagaya V, Mtasiwa D, Mshinda H, Fillinger U, Lindsay SW, Kannady K, de Castro MC, Tanner M, Killeen GF: Interdependence of domestic malaria prevention measures and mosquito-human interactions in urban Dar es Salaam, Tanzania. Malar J 2007, 6:126.

10. Mukabana WR, Kannady K, Kiama GM, ljumba JN, Mathenge EM, Kiche I, Nkwengulila G, Mboera L, Mtasiwa D, Yamagata Y, van Schayk I, Knols BG, Lindsay SW, Caldas de Castro M, Mshinda H, Tanner M, Fillinger U, Killeen GF: Ecologists can enable communities to implement malaria vector control in Africa. Malar J 2006, 5:9.

11. Chanda E, Masaninga F, Coleman M, Sikaala C, Katebe C, Macdonald M, Baboo KS, Govere J, Manga L: Integrated vector management: the Zambian experience. Malar J 2008, 7:164

12. Manga L, Toure A, Shililu J: Implementation of Integrated Vector Management in the WHO African Region. Progress Report 2000-2003 Washington DC: U.S. Agency for International Development 2004

13. Killeen GF, Seyoum A, Knols BG: Rationalizing historical successes of malaria control in Africa in terms of mosquito resource availability management. Am J Trop Med Hyg 2004, 71(2 Suppl):87-93.

14. World Health Organization: Global strategic framework for integrated vector management Geneva: World Health Organization 2004.

15. Snow RW, Craig M, Deichmann U, Marsh K: Estimating mortality, morbidity and disability due to malaria among Africa's non-pregnant population. Bull World Health Organ 1999, 77:624-640.

16. Snow RW, Guerra CA, Noor AM, Myint HY, Hay SI: The global distribution of clinical episodes of Plasmodium falciparum malaria. Nature 2005, 434:214-217.

17. Roberts JMD: Malaria. Health and disease in Kenya Nairobi: East African Literature BureauVogel LC, Muller AS, Odingo RS, Onyango Z, De Geus A 1974, 305-317.

18. Shretta R, Omumbo J, Rapuoda B, Snow RW: Using evidence to change antimalarial drug policy in Kenya. Trop Med Int Health 2000, 5:755-764. 
19. Amin AA, Zurovac D, Kangwana BB, Greenfield J, Otieno DN, Akhwale WS, Snow RW: The challenges of changing national malaria drug policy to artemisinin-based combinations in Kenya. Malar J 2007, 6:72.

20. Noor AM, Alegana VA, Gething PW, Snow RW: A spatial national health facility database for public health sector planning in Kenya in 2008. Int J Health Geogr 2009, 8:13.

21. Noor AM, Gething PW, Alegana VA, Patil AP, Hay SI, Muchiri E, Juma E, Snow RW: The risks of malaria infection in Kenya in 2009. BMC Infect Dis 2009, 9:180.

22. Kiszewski A, Mellinger A, Spielman A, Malaney P, Sachs SE, Sachs J: A global index representing the stability of malaria transmission. Am J Trop Med Hyg 2004, 70:486-498.

23. Mouchet J, Carnevale P, Coosemans M, Julvez J, Manguin S, RichardLenoble D, Sircoulon J: Biodiversité du paludisme dans le monde. Montrouge, France: John Libbey Eurotext 2004.

24. Service MW: The Anopheles vector. Bruce-Chwatt's Essential Malariology London: Edward ArnoldGilles HM, Warrell DA , 3 1993, 96-123.

25. Service MW: Appendix II. Characteristics of some major Anopheles vectors of human malaria. Bruce-Chwatt's Essential Malariology London: Edward ArnoldGilles HM, Warrell DA, Third 1993, 305-310.

26. White GB: Malaria. Geographical distribution of arthropod-borne diseases and their principal vectors Geneva: World Health Organization, Division of Vector Biology and Control 1989.

27. Hay SI, Sinka ME, Okara RM, Kabaria CW, Mbithi PM, Tago CT, Benz D, Gething PW, Howes RE, Patil AP, Temperley WH, Bangs MJ, Chareonviriyaphap T, Elyazar IR, Harbach RE, Hemingway J, Manguin S, Mbogo CM, Rubio-Palis Y, Godfray HC: Developing global maps of the dominant Anopheles vectors of human malaria. PLOS Med 2010, 7: e1000209.

28. Mukiama TK, Mwangi RW: Seasonal population changes and malaria transmission potential of Anopheles pharoensis and the minor anophelines in Mwea Irrigation Scheme, Kenya. Acta Trop 1989, 46:181-189.

29. Jjumba JN, Mwangi RW, Beier JC: Malaria transmission potential of Anopheles mosquitoes in the Mwea-Tebere irrigation scheme, Kenya. Med Vet Entomol 1990, 4:425-432.

30. Hay SI, Snow RW: The Malaria Atlas Project: developing global maps of malaria risk. PLoS Med 2006, 3:e473.

31. PubMed. [http://www.ncbi.nlm.nih.gov/pubmed/].

32. Web of Science. [http://isiwebofknowledge.com/products_tools/ multidisciplinary/webofscience/].

33. AnoBase Bibliographical Database. [http://www.anobase.org/cgi-bin/ publn.pl].

34. Moffett A, Strutz S, Guda N, Gonzalez C, Ferro MC, Sanchez-Cordero V, Sarkar S: A global public database of disease vector and reservoir distributions. PLoS Negl Trop Dis 2009, 3:e378.

35. Lifemapper. [http://www.lifemapper.org/].

36. Mapping Malaria Risk in Africa/Atlas du Risque de la Malaria en Afrique (MARA). [http://www.mara.org.za/].

37. VectorBase. [http://www.vectorbase.org].

38. MalariaWorld database. [http://www.malariaworld.org/search/node/].

39. Malaria in the News (Roll Back Malaria) Archives. [http://www. rollbackmalaria.org/malariainthenews.html].

40. Environmental Health at USAID. [http://www.ehproject.org/]

41. BioMed Central. [http://www.biomedcentral.com].

42. Walter Reed Biosystematics Unit (WRBU) Mosquito Catalog. [http://www. mosquitocatalog.org/default.aspx?pglD=8].

43. Githeko AK, Lindsay SW, Confalonieri UE, Patz JA: Climate change and vector-borne diseases: a regional analysis. Bull World Health Organ 2000, 78:1136-1147.

44. Lindsay SW, Birley $\mathrm{MH}$ : Climate change and malaria transmission. Ann Trop Med Parasitol 1996, 90:573-588.

45. Ministry of Education: Inception Report: Consultancy on development of a G/S database of learning Institutions (School mapping exercise) Oakar Services Ltd 2004.

46. Ministry of Roads and Public Works: Classified Digital Road Network in Kenya Nairobi: Roads Department 2004

47. Microsoft ${ }^{\oplus}$ : Encarta ${ }^{\oplus}$ Reference Library Microsoft Corporation 2007.

48. Google Earth. [http://earth.google.com/].

49. NGA GEOnet Names Server (GNS). [http://earth-info.nga.mil/gns/html/ index.html].
50. Global Gazetteer Version 2.1. [http://www.fallingrain.com/world/]

51. Guerra CA, Hay SI, Lucioparedes LS, Gikandi PW, Tatem AJ, Noor AM, Snow RW: Assembling a global database of malaria parasite prevalence for the Malaria Atlas Project. Malar J 2007, 6:17.

52. Central Bureau of Statistics: 1999 Population and housing Census, population distribution by administrative areas and urban Centers. Nairobi, Kenya 2001, 1.

53. Virtual Terrain Project. [http://www.vterrain.org/Elevation/SRTM/]

54. Coetzee $M$, Craig $M$, le Sueur D: Distribution of African malaria mosquitoes belonging to the Anopheles gambiae complex. Parasitol Today 2000, 16:74-77.

55. Moffett A, Shackelford N, Sarkar S: Malaria in Africa: vector species' niche models and relative risk maps. PLoS One 2007, 2:e824.

56. Rogers DJ, Randolph SE, Snow RW, Hay SI: Satellite imagery in the study and forecast of malaria. Nature 2002, 415:710-715.

57. Coetzee M: Distribution of the African malaria vectors of the Anopheles gambiae complex. Am J Trop Med Hyg 2004, 70:103-104.

58. Levine RS, Townsend Peterson A, Benedict MQ: Geographic and ecologic distributions of the Anopheles gambiae complex predicted using a genetic algorithm. Am J Trop Med Hyg 2004, 70:105-109.

59. Onyabe DY, Conn JE: The distribution of two major malaria vectors, Anopheles gambiae and Anopheles arabiensis, in Nigeria. Mem Inst Oswaldo Cruz 2001, 96:1081-1084

60. Sogoba N, Vounatsou P, Bagayoko MM, Doumbia S, Dolo G, Gosoniu L, Traore SF, Toure YT, Smith T: The spatial distribution of Anopheles gambiae sensu stricto and An. arabiensis (Diptera: Culicidae) in Mali. Geospatial Health 2007, 2:213-222.

61. Sogoba N, Vounatsou P, Bagayoko MM, Doumbia S, Dolo G, Gosoniu L, Traore SF, Smith TA, Toure YT: Spatial distribution of the chromosomal forms of Anopheles gambiae in Mali. Malar J 2008, 7:205.

62. Dia I, Ba H, Mohamed SA, Diallo D, Lo B, Diallo M: Distribution, host preference and infection rates of malaria vectors in Mauritania. Parasit Vectors 2009, 2:61.

63. Julvez J, Mouchet J, Suzzoni J, Larrouy G, Fouta A, Fontenille D: Les anophèles du Niger. Bull Soc Pathol Exot 1998, 91:321-326.

64. Shililu J, Ghebremeskel T, Mengistu S, Fekadu H, Zerom M, Mbogo C, Githure J, Gu W, Novak R, Beier JC: Distribution of anopheline mosquitoes in Eritrea. Am J Trop Med Hyg 2003, 69:295-302.

65. Shililu J, Ghebremeskel T, Seulu F, Mengistu S, Fekadu H, Zerom M, Ghebregziabiher A, Sintasath D, Bretas G, Mbogo C, Githure J, Brantly E, Novak R, Beier JC: Larval habitat diversity and ecology of anopheline larvae in Eritrea. J Med Entomol 2003, 40:921-929.

66. Wondji C, Frederic S, Petrarca V, Etang J, Santolamazza F, Della Torre A, Fontenille D: Species and populations of the Anopheles gambiae complex in Cameroon with special emphasis on chromosomal and molecular forms of Anopheles gambiae s.s. J Med Entomol 2005, 42:998-1005.

67. Smith DL, Hay SI, Noor AM, Snow RW: Predicting changing malaria risk after expanded insecticide-treated net coverage in Africa. Trends Parasitol 2009, 25:511-516.

68. Robert V, Awono-Ambene HP, Thioulouse J: Ecology of larval mosquitoes, with special reference to Anopheles arabiensis (Diptera: Culcidae) in market-garden wells in urban Dakar, Senegal. J Med Entomol 1998, 35:948-955.

69. Matthys B, N'Goran EK, Kone M, Koudou BG, Vounatsou P, Cisse G, Tschannen $A B$, Tanner $M$, Utzinger J: Urban agricultural land use and characterization of mosquito larval habitats in a medium-sized town of Cote d'Ivoire. J Vector Ecol 2006, 31:319-333.

70. Afrane YA, Klinkenberg E, Drechsel P, Owusu-Daaku K, Garms R, Kruppa T: Does irrigated urban agriculture influence the transmission of malaria in the city of Kumasi, Ghana? Acta Trop 2004, 89:125-134.

71. Impoinvil DE, Keating J, Mbogo CM, Potts MD, Chowdhury RR, Beier JC: Abundance of immature Anopheles and culicines (Diptera: Culicidae) in different water body types in the urban environment of Malindi, Kenya. J Vector Ecol 2008, 33:107-116.

72. Impoinvil DE, Mbogo CM, Keating J, Beier JC: The role of unused swimming pools as a habitat for Anopheles immature stages in urban Malindi, Kenya. J Am Mosq Control Assoc 2008, 24:457-459.

73. Elith J, Graham CH, Anderson RP, Dudik M, Ferrier S, Guisan A, Hijmans RJ, Huettmann F, Leathwick JR, Lehmann A, Li J, Lohmann LG, Loiselle AB, Manion G, Moritz C, Nakamura M, Nakazawa Y, Overton J, Peterson Townsend A, Phillips SJ, Richardson K, Scachetti-Pereira R, Schapire ER, Soberón J, Williams JS, Wisz SM, Zimmermann NE: Novel methods improve 
prediction of species' distributions from occurrence data. Ecography 2006, 29:129-151.

74. Scharlemann JP, Benz D, Hay SI, Purse BV, Tatem AJ, Wint GR, Rogers DJ: Global data for ecology and epidemiology: a novel algorithm for temporal Fourier processing MODIS data. PLoS One 2008, 3:e1408.

75. Hay SI, Tatem AJ, Graham AJ, Goetz SJ, Rogers DJ: Global environmental data for mapping infectious disease distribution. Adv Parasitol 2006 62:37-77.

76. Malaria Atlas Project (MAP). [http://www.map.ox.ac.uk].

doi:10.1186/1475-2875-9-69

Cite this article as: Okara et al:. Distribution of the main malaria vectors in Kenya. Malaria Journal 2010 9:69.

Submit your next manuscript to BioMed Central and take full advantage of:

- Convenient online submission

- Thorough peer review

- No space constraints or color figure charges

- Immediate publication on acceptance

- Inclusion in PubMed, CAS, Scopus and Google Scholar

- Research which is freely available for redistribution

Submit your manuscript at www.biomedcentral.com/submit 